\title{
DECONSTRUCTION IN PAINTING: AN APPLICATION OF DECONSTRUCTION THEORY IN SELECTED PAINTINGS OF PABLO PICASSO
}

\author{
Alireza Anushiravani ${ }^{1}$ and Seyedeh Sara Foroozani ${ }^{2 *}$ \\ ${ }^{1}$ Associate Prof., Shiraz University, Iran, anushir@shirazu.ac.ir \\ ${ }^{2}$ M.A. Student, Shiraz University, Iran, hforoozanih@gmail.com \\ ${ }^{*}$ Corresponding author
}

"Every act of creation is first an act of destruction" (Pablo Picasso)

\begin{abstract}
Having been always associated with the French theoretician Jacques Derrida, the term 'Deconstruction' happened to become the greatest revolutionary theory proposed in the twentieth century. As the term points to, deconstruction theory tends to deny any sort of fixed stable system of predicted rules and meanings in art. Rather, it offers an existing infinity and flexibility in meaning as an inborn entity in the discussion of art interpretation. Deconstruction theory, further concentrates itself on the active role, an audience's ideologies and individuality operate during the process of his/her interpretation of a piece of art, while insisting on cultural parameters. The current article aims to reveal how deconstruction can help critics and individuals to reach a worldwide multidimensional understanding and appreciation of any genre of art by applying its major applications of binary oppositions and ideological privileged on two selected works of the famous twentieth century painter, Pablo Picasso. Hence, shedding a new light of understanding on Picasso's works by seeking to curve out his ideological privileges and proposing new possible relationships between the concepts and the meanings in his paintings. In this regard it must be noted that deconstruction focuses on two major points in its applications; the first one deals with the uncertainty of an artistic work as a mean to reveal the selfcontradictory and multiplicity of the thematic meanings proposed by both the artist and the audience, and the second point focuses on the underlying ideological dimensions within the artifact. Finally, it is believed that artist's ideological frameworks can be decoded by applying deconstruction theories on his/her artifacts.
\end{abstract}

Keywords: Jacques Derrida, Deconstruction, Twentieth Century, Art, Binary opposition, Ideological privileges, Pablo Picasso

\section{AN INTRODUCTION TO MODERNISM AND CUBISM}

Art and society are two interrelating, yet opposing collective entities which cannot operate independently of one another. There is always a "mutual demand" (Pakbaz, 2013, p. 15) between the two, however mutual acceptance rarely occurs. This is the point, where the role of an artist gets highlighted, as a leading figure who endeavors to bring back the art and society in close association. Modern era was the time when art and society experienced the deepest clash between an artist's "value system" (Pakbaz, 2013, p. 15) and his/her society. It was the era in which a materialistic view toward life was governing human beings and their social 
relations, while Modern artists were struggling to bring "morality back to humanity" (Pakbaz, 2013, p. 15) through their art.

Modernism in its artistic sense, tended to neglect and later destroy the "great artistic traditions" (Pakbaz, 2013, p. 15) of the Greek and Roman, in favor of the confusion and the complexity of the era which demanded a sort of revolutionary deconstructive approach. Thus, a passage away from the great academic artistic traditions of the Greek and Roman was required. The shift was guided toward the modern schools of "Expressionism, Cubism, Surrealism" (Pakbaz, 2013, p. 16), which was a turning point from those realistic parallel to nature portraits to the exposition of a real image of what an artist perceives as the true operating gist of his/her art by clinging to certain signifiers such as colors, lines, shapes which later on resulted in the absence of "visual reality" (Pakbaz, 2013, p. 16) or the full disappearance of the real image in its physical sense in Expressionism and Cubism.

Having a brief discussion about the two pioneer interrelated schools of art in Modern era, Expressionism, the non-conformist boisterous child of Germany born as "a new approach to life, or better to call it an apocalypse" (Seyed Hosseini, 2012, p. 700). It was a "rebellion against the ambiguous confused aestheticism"; "a definition for the torture and sadness" imposed on Modern civilization. Expressionism goes far beyond those merely aesthetic frameworks and criticism of the previous period and clings to the deepest concepts of "religion, philosophy, politics and society" (Seyed Hosseini, 2012, p. 701). Hence, it seeks to manifest human condition and emotions of Modern people, as truly and realistically as it is. In terms of its ideological and stylistic method, Expressionism denies "tradition" (Seyed Hosseini, 2012, p. 701) in all senses, it rises against the "order and discipline" with a strong tendency toward the "excessiveness and deconstruction of the old familiar values" (Seyed Hosseini, 2012, p. 701). This is the very reason behind why many critics associate themes of "revolution, excitement, change, freedom, passion" (Seyed Hosseini, 2012, p. 701) as recurring in Expressionistic works of art.

However it was during the first decades of early $20^{\text {th }}$ Century and under full domination of Expressionism in art that Cubism emerged. Cubism was an effort in "creating new images not comparable with any real existing object" (Gunther Buchheim, 1959, p. 88) through the practice of "different levels of eye-deceiving" and the "return of colors" to the canvas which implied a deep emotion for its audience by the "active coexistence of colorful surfaces" (Gunther Buchheim, 1959, p. 87). Paradoxically and in sharp contrast with Expressionism that sought to "declare the most unique personal emotions of an artist" (Seyed Hosseini, 2012, p. 731), Cubism, mostly associated with works of the Spanish artist Pablo Picasso, was an effort toward a brand new "projection of objects and entities in a geometric combinatory manner" (Seyed Hosseini, 2012, p. 731). It was an invitation for appreciation of art, beyond its superficial artistic values and toward discovering invisible mystical sides of an artistic work by "visualizing its all-sided angles" (Seyed Hosseini, 2012, p. 731). Thus, Cubism distances art and painting in specific, from Realism, by its collage-like method of selection, collection and connection of objects and emotions of an artist in an instant moment, reflected on a canvas as a camera shot image.

Cubism then emerged in Literature of the Modern period through the works of Guillaume Apollinaire (18801918), as a school which favored a holistic view of a literary work. It was an interesting approach in literature that tended to deconstruct all of the "familiar arrangement and composition" (Seyed Hosseini, 2012, p. 732) and the internal mental and physical connections existing within a certain object and its relation with individuals. It then reconstructs a new set of "logical" connections (Seyed Hosseini, 2012, p. 732) and organizations by setting those objects in new structure and form. Hence, Cubism was a "visual space discovery" (Gardner et al., 1996, p. 622) in a sense that it was an "inclusion of real forms in spatial frameworks in which the two-dimensional surface and the three-dimensional illusory effects get compatible in a subtle elegant way" (Gardner et al., 1996, p. 621). Cubism was based on the major principles of "simplified images", "mobile view angle" and "simultaneous presentation of heterogeneous surfaces" (Gardner et al., 1996, p. 622), which in turn enabled the audience to look at a certain object from different point of views.

In terms of deconstruction, "art is precisely antithetical to knowledge; it works against what Lyotard once called the 'fantasies of realism', meaning the art is considered to be both "a part of the world" and "a part from the world" (O'sullivan, 2001, p. 25). Deconstruction is "understanding art as being in the crisis of representation; appealing to origins as final explanation, and then putting the notion of origin under erasure" (O'sullivan, 2001, p. 26) and then the result would be what O'sullivan defines as "affects" (26), as the "extradiscursive and extra-textual" (26). However, O'sullivian asserts that "affects [can sometimes be only] meaningful within language" (26). It worth noticing that "in the realm of virtual [since there is always a distance between the audience and both the artifact and the artist, physically and emotionally], art-art workis no longer an object as such, or not only an object, but rather a space, a zone or what Alain Badiou might call an 'event site' ... [the place] where one might encounter the affect" (O'sullivan, 2001, p. 27). Regarding 
the issue of affect, there is another term in discussion of deconstruction in art as "a block of sensation, [that is] waiting to be reactivated by a spectator or participant . . . which brings us to the crux of the matter: experience ... [which in turn] implies the necessary experience of any present as a passing experience, that makes the past irrevocable and unforgettable, because it is inseparable from any present or future" (O'sullivan, 2001, p. 26).

Being associated with "discourse that surrounds it" (O'sullivan, 2001, p. 27), deconstruction regards us parallel with subjects, as "bundles of events, bundles of affects ... [as sets of] practices and strategies which reveal this 'other side' to ourselves" (O'sullivan, 2001, p. 28). This is the very gist of art, "to switch our intensive register, to reconnect us with the world ... [a]nd we, as spectators, as representational creatures, are involved in a dance with art, a dance in which- through careful maneuvers- the molecular is opened up, the aesthetic is activated, and art does what is its chief modus operandi: it transforms . . . our 'selves' and our notion of our world" (O'sullivan, 2001, p. 28).

Many critics believe that "art is situated on the borderline between the actual and the virtual [which promotes] art an ethical imperative [power]" (O'sullivan, 2001, p. 29). But, as O'sullivan notes, what scares them is the danger they argue lies in here:

$[T]$ hat the virtual could be confused with the possible. The possible is opposed to the real; the process undergone by the possible is therefore a 'realization'. By contrast, the virtual is not opposed to the real; it possesses a full reality by itself. The process it undergoes is actualization. It would be wrong to see only a verbal dispute here: it is a question of existence itself (29).

However, such discussions are believed to be subsidiary, while there are still crucial points to be talked about in the realm of art. In terms of art and specifically those forms of art which are visual, as painting, one must refer to the most central point among them as "a sensory engagement" (Cranny-Francis, 2012, p. 8). This in turn refers to the spectators' "internal and vestibular" sense of self and balance (Cranny-Francis, 2012, p. 9), meaning that the "vestibular senses are engaged to the position of the viewer close to the work . .. in a way that demands somatic, emotional and intellectual awareness" (Cranny-Francis, 2012, p. 13). In line with what has been said, art in modern sense switched toward "the stylization and abstraction of modernist art to focus on the everyday" (Cranny-Francis, 2012, p.12), it concerned itself about "physicality" as an "intense awareness of the body as being and not as separate from, or simply a carrier of being" (Cranny-Francis, 2012, p. 19). However in terms of Picasso's portraits, the point is that by being life-sized but not life-like, the "viewers are challenged to consider how [his] choice of material [and style] contributes to the meaning of the works" (Cranny-Francis, 2012, p. 23). For instance, oil color was used to be practiced in realistic paintings by traditional painters, when Pablo Picasso tended to deconstruct its traditional role by depicting it in his cubist and surrealist oil paintings. This was the beginning point for deconstruction to enter painting through challenging "the conventional dichotomy" of vision (Cranny-Francis, 2012, p. 24).

The current article seeks to brings analytical instances of the potentiality that lies in every sort of art, and also what it actually means to discover the existing bipolarity and then to deconstruct a painting by the use of its own operating theme. The two chosen paintings belong to one of the greatest Spanish artists of Modern era, Pablo Picasso, both of which are in Cubist style and contemporary to one another.

\section{PICASSO'S PORTRAIT OF THE GIRL BEFORE A MIRROR (1932)}

The first painting to be discussed is Girl before a mirror, painted in 1932 by Pablo Picasso in oil color Cubist style. As the name also suggests, the spectators certainly do expect to see a reflection of a girl on the mirror portrayed on the canvas, which is the case as well. The first thing that attracts the viewers in the first place is the dominant use of purple and bluish purple colors, mostly on the side of the reflected image in the mirror. Violet or purple as secondary colors which can be attained through a mixture of two primary colors (here red and blue of the color wheel), are considered as having potentialities of imposing both warm and/or cold sensations. However, in this painting we are mostly dealing with blue-purple colors, so the cold sensation is artistically revealed to the spectators by Picasso.

To deconstruct this painting, one must refer to the most dominant binary opposition, operating the work that would be the images of the two girls, one with her physicality, portrayed in two half paradoxically through a sort of direct compliments, which are those two contrasting colors, placed adjacent to one another. One side of the girl is drawn by lighter colors consisted of very pale green, yellow and purple colors in juxtaposition of some white and the other part is painted with a warmer sense of the same colors used on the first side, which are yellow, green and purple, all in darker fashion plus a use of dark brown and reddish brown. The first side is believed to be more associated with physical world because of its more realistic presentation of body images, while the second part reveals the existence of subconscious side of the girl, a sense of 
spirituality through the use of various tones of the purple color. Another point is the use of red in both the second part and in the reflected image.

The red color is an intense color in emotional sense, it is the color of energy and stimulation with the capacity of high visibility among other colors which in turn makes it privileged in paintings in comparison with other thematic used colors. It is also noteworthy to mention that the red color is used in specific points around and inside the head and hand part of the figure, while the first side is drawn empty of it, and it seems that the physical side is clinging to spirituality from the mirror side.

After the analysis of both poles of the binary opposition, the next step is to find the privilege point between the two sides, which in this case would be the second side of the girl, the one which is in strong connection and attachment with the image reflected on the mirror. Interestingly enough, the second side of the girl along with the reflected image can be anticipated as united because of their unity of used colors among them and the united part consists around $2 / 3$ of the whole painting. The orange frame of the mirror that has held the reflected girl is the combination of the red, as the color of energy and the yellow as associated with happiness and joy as in sunshine. Orange represents stimulation, thirst, passion, aggression, attraction and heat. It is the color of harvest and enthusiasm, the mental and spiritual harvest. The red and orange color are also used as the operating theme at the back of the painting, mostly behind the physical side of the girl to which she is ignorant, so Picasso did imposed the hints in front of the figure in shape of the mirror frame to make her alert of the existing but forgotten spiritual, yet thirsty energy and passion inside her.

To resolve the superficial conflict between the existing binary oppositions in this painting, one must refer to the way the back and forth sides of the girl are portrayed as reversed. For instance, the back of the physical side is reflected and placed in the front side of the mirror image with the reversal of the role of the used colors of black and pale green in the striped pattern. This is also the case with the red and yellow colors used both in the reflected image, as the spiritual side and at the back of the physical side as its supporting factor. Finally, all colors are used in both images and both sides, even though in reversed patterns. It seems that there is a sense of physicality and a sense of spirituality mingled in both images in the portrait, as it is the case with every individual through the juxtaposition of cold and warm colors in the painting.

\section{PICASSO'S PORTRAIT OF LE REVE (1932)}

The next art work to be deconstructed is Le Reve, portrayed in 1932 in oil color style. The figure in the painting is said to be his 22 years old mistress, Marie Therese. The first prominent point to be discussed lies in the way Picasso tented to divide the main image and the thematic scene into two even parts quite subtly through a clever choice of angle to the scene. The chair on which the girl is slept is believed to have been set in the corner between two walls, as the pattern and the colors of the background suggests. The model has also followed the division trend in upper half of the body by a linear invisible line in her chest area and by a black line in the head part as a symbol of depth, mysteriousness and more significantly to highlight the distinction between the two parts through the bold paradoxical contrast between the colors of white and black. Thus, it is believed that the privileged part is the left side because of its higher level of complexity and realism (being associated with physical aspects like possessing hair and the red necklace) and of course because of the head orientation toward the left side of the painting.

Being red and yellow in color, the couch is perceived as possessing the girl's unconsciousness, the storehouse of desires and passions which is allowed to be revealed only in dreams. The color of the hair yellow and it is highly suggestive of energy, intellectualism and mental activity in a sense that affects the physics. So the left side of the body seems to be the representative of the intellectual and logical side of an individual. On the other hand, the thematic green background as opposed to red, connotes the sensation of safety an individual experiences through his/her dream in parallel with the use of white color at the same side which refers to perfection as well. The privileged side seems to have covered the sexual part of the upper half of the girl's body, while being the representative of passionate emotion, the other side has revealed the organ in an obvious manner. The color of green also refers to the naivety of the central figure. It is also worth noticing that the necklace gets yellowish on the second part which is suggestive of energy, attention and joy.

Another interesting point is that the sexually attractive parts on the female figure's body, namely the neck, the breast part and etc. are portrayed by blue color, which is considered to be a masculine color, thus the one which reveals male psychological view angle toward female. The emotional side of the body is also in connection with the brown colored wall patterned with reddish flower, which is connotative of the earthly desires and dependability of the figure. However, the juxtaposition of the two walls, along with the peaceful presentation of the girl in line with the title it has possessed (Le Reve meaning The Dream) refers to the 
current harmony and stability of the both poles with an individual, as it is the case with the two parts of the girl's necklace which belong to a single unity, while being composed of two differing colors.

In sum, the result of an artistic survey as both Derrida and De Man refer is the affect, the momentary experience of an individual happening through the deconstruction of an art and is perceived through the unconscious, thus it is unattainable to the conscious part of the psyche, thus it is referred to as echo and representation of the feeling by the conscious part. It also worth referring back to the way Derrida's analytical method of deconstruction deals with the criticism of metaphysical presence and essence, meaning that there is no consistent predictable sort of narrative language operating in art. It is rather the internal dual system within every piece of work that brings up the issue of difference and instability and deconstruction happens exactly in in its moment of instability and conflicts. This in turn leads to the superficial feature of fluctuation of an artistic work, however deconstruction reveals the way such conflicts and dualities in effect come into relation in favor of a great unity, even in those complex Cubist paintings of the Modern era.

\section{REFERENCE LIST}

Cranny-Francis, Anne. (2012). Sculpture As Deconstruction: The Aesthetic Practice Of Ron Mueck. Visual Communication $12(1)$.

Gardner, H., Tansey, R. G., \& Kleiner, F. S. (1996). Gardner's Art Through The Ages. Fort Worth: Harcourt Brace College Publishers.

Gunther Buchheim, Lothar. (1959). Picasso, A Pictorial Biography. New York: Thames and Hudson.

O'sullivan, Simon. (2001). The Aesthetics Of Affect: Thinking Art Beyond Representation. ANGELAKI: Journal of The Theoretical Humanities 6 (3).

Pakbaz, Rooeen. (2013). In Search of a New Language. Tehran: Negah Publication.

Seyed Hosseini, Reza. (2012) Literary Schools. 2nd ed. Vol. 2. Tehran: Negah Publication. 